\title{
KAJIAN PERSEPSI MASYARAKAT DKI JAKARTA TERHADAP KAWASAN URBAN HERITAGE GELORA BUNG KARNO
}

\section{THE PERCEPTION STUDY OF THE COMMUNITY OF JAKARTA TO THE GELORA BUNG KARNO URBAN HERITACE AREA}

\author{
Aditio Setionurjaya', Wido Prananing Tyas ${ }^{2}$ \\ 'Direktorat Jenderal Cipta Karya; Kementerian Pekerjaan Umum dan Perumahan Rakyat; aditio.setionurjaya@gmail.com \\ ²Departemen Perencanaan Wilayah dan Kota; Universitas Diponegoro, Semarang, Jawa Tengah; w.p.tyas@pwk.undip.ac.id
}

Info Artikel:

- Artikel Masuk: 28/07/18

- Artikel diterima: $13 / 08 / 18$

- Tersedia Online: 24/08/18

\begin{abstract}
ABSTRAK
Kompleks Gelanggang Olahraga (Gelora) Bung Karno merupakan ruang publik olahraga dan rekreasi yang telah ditetapkan sebagai cagar budaya melalui Surat Keputusan Gubernur DKI Jakarta Nomor 475 Tahun 1993, dikelilingi area komersial modern bertingkat tinggi dan kemacetan di sekitar kawasan, yang dapat mengancam identitas sebagai urban heritage. Sesuai amanat UU Nomor 11 Tahun 2010 tentang Cagar Budaya, masyarakat juga turut serta dalam upaya pelestarian, terutama masyarakat DKI Jakarta. Penelitian ini bertujuan untuk mengidentifikasi karakteristik dan persepsi masyarakat DKI Jakarta terhadap makna dan fungsi ruang publik olahraga Kompleks GBK sebagai urban heritage, yang belum pernah dilakukan sebelumnya. Metode penelitian menggunakan metode deskriptif kuantitatif, dengan teknik pengambilan sampel non probability sampling. Teknik pengumpulan data dilakukan melalui penyebaran kuesioner, wawancara, observasi lapangan, telaah dokumen, dan studi literatur. Pengolahan data dilakukan melalui analisis deskriptif kuantitatif dengan metode distribusi frekuensi. Hasil penelitian menunjukkan bahwa sebagian besar pengunjung dari DKI mengakui bahwa Kompleks GBK merupakan urban heritage yang mempunyai makna dan fungsi bagi masyarakat DKI Jakarta, namun ada pula yang kurang meyadari pentingnya fungsi urban heritage. Oleh karena itu, pengelola dapat untuk memberikan informasi dan pemahaman tentang cagar budaya di Kompleks GBK, dan juga mengoptimalkan kerjasama dengan berbagai pihak untuk pengembangan GBK, tidak hanya dalam bidang pariwisata namun juga tetap berfungsi sebagai fasilitas olah-raga .

Kata Kunci : cagar budaya, konservasi, persepsi masyarakat
\end{abstract}

\section{ABSTRACT}

Gelora Bung Karno (GBK) Complex is a sports and recreation public space that has been appointed as a heritage through Jakarta Governor's Decree No. 475/1993, surrounded by modern high-rise commercial area and congestion around the area, that can threaten GBK's identity as urban heritage. In accordance with the mandate of Law Number 11 Year 2010 on Heritage, the community also participated in conservation efforts, especially the people of Jakarta. This study aims to identify the characteristics and perceptions of the people of Jakarta towards the meaning and function of the GBK Complex sports public space as urban heritage, that has never been done before. The research method uses quantitative descriptive method, with the sampling technique used is non probability sampling. Data collection techniques were conducted through questionnaires, interviews, field observations, document review, and literature studies. Data processing is done through quantitative descriptive analysis with frequency distribution method. The results showed that most of the visitors from DKI Jakarta admitted that the GBK Complex was an urban heritage that had meaning and function for the people of DKI Jakarta, however there was a small percentage of community felt that GBK as urban heritage. In doing so, with recommendations for the management to provide information and understanding of heritage in the GBK Complex, and also make a partnership for GBK developmentby both as a tourism object and sport venue.

Keyword: heritage, conservations, community perceptions

Copyright $\odot 2018$ JPWK-UNDIP This open access article is distributed under a Creative Commons Attribution (CC-BY-NC-SA) 4.0 International license.

Cara men-sitasi (APA 6th Style):

Setionurjaya, Aditio, \& Tyas, Wido P. (2018). Kajian Persepsi Masyarakat DKI Jakarta Terhadap Kawasan Urban Heritage Gelora Bung Karno. Jurnal Pembangunan Wilayah dan Kota, Vol 14 (2), 83 - 93 


\section{PENDAHULUAN}

Urban heritage (pusaka perkotaan) merupakan komponen penting yang berperan dalam membentuk karakter, identitas dan citra kota, yang menunjukkan kondisi sosial dan intelektual, melingkupi masa lalu, masa kini dan masa depan, serta dilihat sebagai kesan dari pola dan perilaku mayoritas masyarakat lokal (Petronela, 2016). Konsep heritage atau cagar budaya tersebut berasal dari unsur-unsur fisik dan nonfisik termasuk nilai sentimentalnya, yang ditegaskan dengan adanya peraturan resmi agar masyarakat dapat mengetahui, mempelajari, menjaga, serta mengakses benda pusaka tersebut (Versaci, 2016). Pengabaian terhadap perlindungan cagar budaya akan menyebabkan kerugian yang signifikan baik di bidang ekonomi dan sosial (termasuk sektor pariwisata) (Claudia dan Luigi, 2016). Perlindungan cagar budaya dilakukan di segala tingkatan, baik oleh badan pemerintah maupun non-pemerintah. Di Indonesia, cagar budaya diatur dalam Undang-Undang Nomor 11 tahun 2010, yang mendefinisikan bahwa cagar budaya adalah warisan budaya bersifat kebendaan di darat dan/atau di air yang perlu dilestarikan keberadaannya karena memiliki nilai penting bagi sejarah, ilmu pengetahuan, pendidikan, agama, dan/atau kebudayaan melalui proses penetapan.

Dalam konteks bangunan bersejarah, pelestarian atau konservasi adalah penggunaan bangunan tanpa mengubah atau menghancurkan karakteristik ataupun detail bangunan, meskipun perbaikan atau perubahan tersebut mungkin diperlukan (Curl, 2000 dalam Azizi et al., 2016). Dikaitkan dengan urban heritage, pelestarian adalah proses terpadu di mana kota-kota bersejarah diintervensi guna memperbaiki kondisi fisik kawasan terbangun, termasuk bangunan-bangunan bersejarah dan kondisi sosial ekonomi masyarakat (Nour, 2012). Secara garis besar, ada tiga metode utama yang dapat digunakan untuk merawat bangunan bersejarah (Ismail dan Nadarajah, 2016), yakni dengan menjaga bentuk dan fungsi bangunan sesuai aslinya, dengan mengubah fungsi bangunan namun mempertahankan bentuk bangunan aslinya, atau dengan menghancurkan seluruh bangunan dan membangun kembali dengan bentuk baru.

Dalam melakukan pelestarian, diperlukan kriteria untuk mengkaji kelayakan lingkungan bersejarah. Snyder dan Catanese (1979) serta James Semple Kerr (1983) dalam Budihardjo (2011) menyebutkan bahwa tempat atau bangunan yang dikonservasi dipilih berdasarkan beberapa tolok ukur, meliputi:

a. Kelangkaan, yaitu berjumlah sangat langka, tidak terdapat di daerah lain, atau merupakan contoh terakhir.

b. Kesejarahan, yaitu lokasi yang merupakan tempat berlangsungnya peristiwa bersejarah yang penting.

c. Estetika, yaitu mempunyai bentuk, struktur, atau ornamen yang indah.

d. Superlativitas, yaitu memiliki keistimewaan misalnya tertua, tertinggi, terpanjang.

e. Kejamakan, yaitu bersifat tipikal dan dapat mewakili suatu jenis atau ragam.

f. Kualitas pengaruh, yaitu keberadaannya akan mempengaruhi dan meningkatkan citra lingkungan di sekitarnya.

g. Nilai sosial, bagi bangunan yang bermakna bagi masyarakat umum,

h. Nilai komersial, berkaitan dengan peluang untuk dimanfaatkan bagi kegiatan ekonomi, dan

i. Nilai ilmiah, berhubungan dengan peranannya dalam rangka pendidikan dan pengembangan ilmu.

Karakter kota dapat diciptakan oleh adanya ruang publik, yang biasanya dimanfaatkan masyarakat untuk interaksi sosial, ekonomi, dan apresiasi budaya (Darmawan, 2003). Menurut Carr et al. (1992) dan Carmona et al. (2003), ruang publik adalah ruang bersama yang digunakan oleh masyarakat dalam melakukan aktifitas yang mengikat sebuah komunitas, baik itu kegiatan yang rutin dilakukan setiap hari maupun kegiatan yang periodik, yang dapat dicapai secara gratis ataupun berupa ruang privat yang menyediakan akses terbuka bagi publik. Secara garis besar, fungsi ruang publik (Darmawan, 2009) adalah:

a. Sebagai pusat interaksi dan komunikasi masyarakat baik formal maupun informal

b. Sebagai ruang penampung, pengikat, pembagi, dan transit (dilihat dari struktur kota)

c. Sebagai ruang kegiatan ekonomi bagi pedagang dan penjual jasa

d. Sebagai paru-paru kota dan ruang evakuasi apabila terjadi bencana (dalam konteks khusus outdoor). 
Sebagai pusat interaksi dan komunikasi masyarakat, salah satu kegunaan ruang publik adalah dapat dimanfaatkan sebagai tempat berolahraga. Berdasarkan Undang-Undang Republik Indonesia Nomor 3 Tahun 2005 Tentang Sistem Keolahragaan Nasional, secara garis besar olahraga meliputi kegiatan:

a. Olahraga pendidikan, yaitu pendidikan jasmani dan olahraga yang dilaksanakan sebagai bagian proses pendidikan yang teratur dan berkelanjutan untuk memperoleh pengetahuan, kepribadian, keterampilan, kesehatan, dan kebugaran jasmani.

b. Olahraga rekreasi, yaitu olahraga yang dilakukan oleh masyarakat dengan kegemaran dan kemampuan yang tumbuh dan berkembang sesuai dengan kondisi dan nilai budaya masyarakat setempat untuk kesehatan, kebugaran, dan kegembiraan.

c. Olahraga prestasi, yaitu olahraga yang membina dan mengembangkan olahragawan secara terencana, berjenjang, dan berkelanjutan melalui kompetisi untuk mencapai prestasi dengan dukungan ilmu pengetahuan dan teknologi keolahragaan.

Jakarta mempunyai banyak bangunan/kawasan bersejarah, salah satunya adalah Kompleks Gelanggang Olahraga (Gelora) Bung Karno. Kawasan olahraga yang dikelola Kementerian Sekretariat Negara melalui Pusat Pengelolaan Komplek Gelora Bung Karno (PPKGBK) ini ditetapkan sebagai cagar budaya melalui Surat Keputusan Gubernur DKI Jakarta Nomor 475 Tahun 1993 tentang Penetapan Bangunan-Bangunan Bersejarah di Daerah Khusus Ibukota Jakarta Sebagai Benda Cagar Budaya. Kompleks Gelora Bung Karno (GBK) merupakan kawasan olahraga bertaraf internasional pertama di Indonesia, yang didirikan pada tahun 1960 sampai dengan 1962, untuk persiapan penyelenggaraan Asian Games IV tahun 1962. Setelah itu, ketika tidak ada event olahraga, Kompleks GBK menjadi ruang publik bagi semua elemen masyarakat, di mana masyarakat umum boleh menggunakan sarana dan prasarana di Kompleks GBK.

Penggunaan fasilitas di Kompleks GBK oleh masyarakat umum yang tidak terkontrol beresiko terhadap hilang atau rusaknya sarana dan atau prasarana di dalam kawasan tersebut. Kekurangtahuan masyarakat awam dalam hal pelestarian bisa berdampak negatif terhadap eksistensi Kompleks GBK sebagai kawasan cagar budaya yang menjadi urban heritage Jakarta. Selain itu, juga terdapat bangunanbangunan komersial bertingkat yang menjulang serta kemacetan di jalanan di sekitarnya, yang jika tidak terkendali dapat mengaburkan identitas urban heritage dari Kompleks GBK. Sesuai amanat UndangUndang Nomor 11 Tahun 2010 tentang Cagar Budaya, masyarakat terutama yang tinggal di Jakarta juga harus peduli dan turut serta dalam upaya pelestarian kawasan bersejarah tersebut. Namun, pemahaman orang terhadap pelestarian cagar budaya berbeda-beda antara satu dengan yang lain. Oleh karena itu, diperlukan penelitian untuk mengetahui persepsi masyarakat terhadap Kompleks GBK sebagai kawasan urban heritage.

Tujuan dari penelitian ini adalah melakukan kajian persepsi masyarakat DKI Jakarta terhadap Kompleks Gelora Bung Karno sebagai kawasan urban heritage. Penelitian ini diharapkan dapat berkontribusi positif dalam ilmu perencanaan wilayah dan kota terkait persepsi masyarakat terhadap ruang publik cagar budaya. Penelitian tentang persepsi masyarakat terhadap cagar budaya berupa kawasan olahraga yang sekaligus berfungsi sebagai ruang publik belum pernah dilakukan sebelumnya. Di sisi lain, hasil penelitian dapat menjadi masukan bagi masyarakat terkait perlunya pemahaman mengenai kawasan cagar budaya, serta masukan bagi pemerintah dan pengelola dalam melestarikan Kompleks Gelora Bung Karno.

\section{DATA DAN METODE}

2.1. Wilayah Penelitian

Kompleks Gelora Bung Karno (GBK) berada di dalam lingkup Kelurahan Gelora, Kecamatan Tanah Abang, Kota Jakarta Pusat. Sebagai kawasan yang dibangun untuk olahraga, luas awalnya 279,1 hektar. Pada perkembangannya, oleh karena adanya perubahan fungsi dari sebagian lahannya, luas lahannya kini menyusut menjadi 136,84 hektar. Kompleks GBK dibatasi oleh Jalan Gerbang Pemuda di sebelah utara, Jakarta Convention Center dan Hotel Sultan di sebelah timur, Jalan Pintu Satu Senayan di sebelah selatan, serta Jalan Asia Afrika di sebelah barat. Sebagai kawasan yang dari awal diperuntukkan bagi olahraga, 
aktifitas yang terdapat di Kompleks GBK didominasi oleh kegiatan olahraga, sehingga di situ banyak fasilitas olahraga, baik itu untuk olahraga prestasi maupun untuk olahraga ringan dan rekreasi. Wujudnya pun beragam, ada yang berupa bangunan tertutup, ada juga yang berupa lapangan terbuka. Berikut ini adalah lokasi Kompleks GBK beserta letak fasilitas-fasilitas olahraga prestasi maupun rekreasi yang terdapat di dalamnya yang tergambar dalam Gambar $\mathbf{1}$.

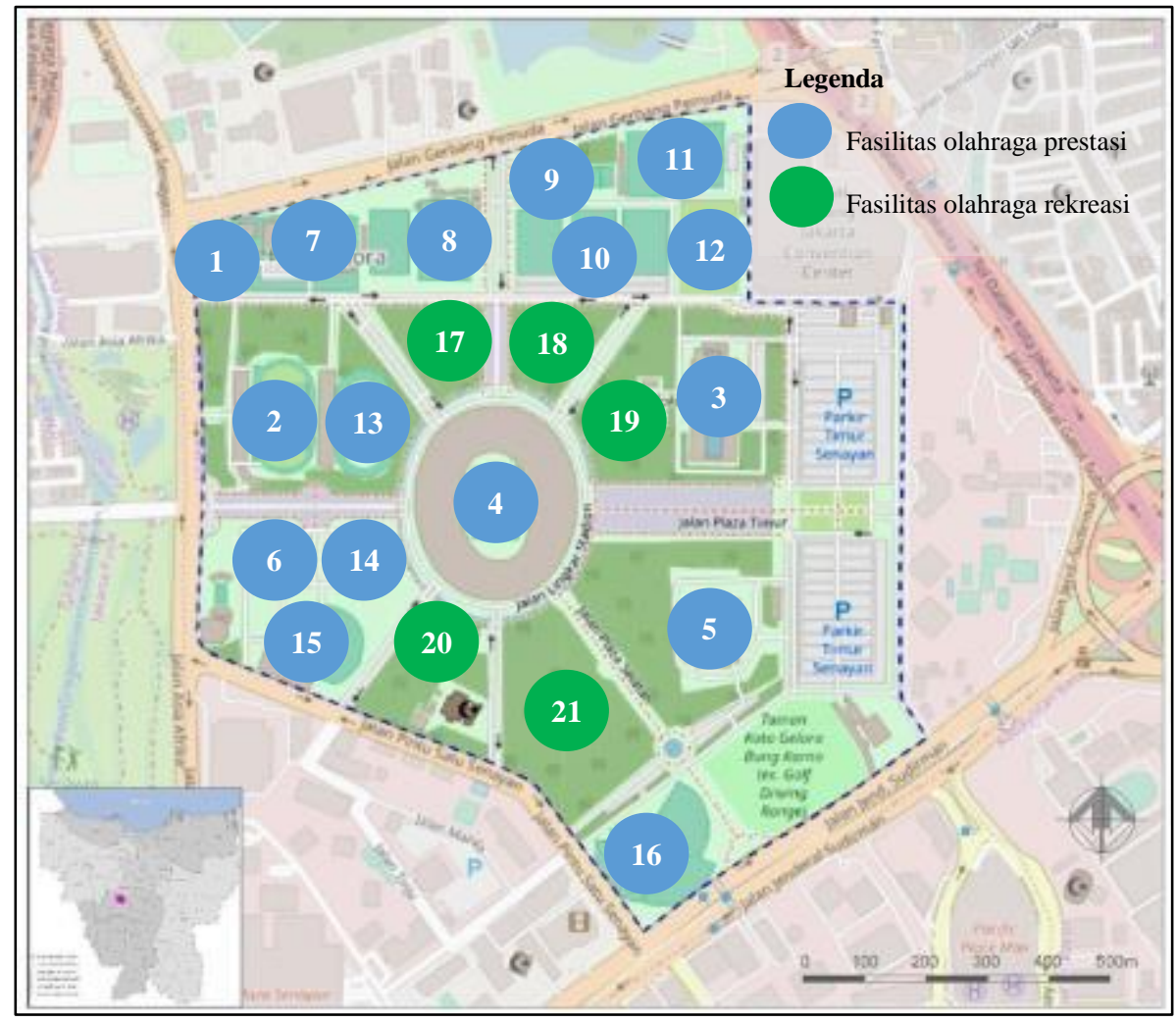

\section{Keterangan}

1) Gedung Basket

2) Stadion Madya

3) Stadion Akuatik

4) Stadion Utama

5) Istora

6) Stadion Tenis Outdoor

7) Gedung Squash

8) Lapangan Panahan

9) Lapangan Basket 3 on 3

10) Lapangan $A, B, C$

11) Lapangan Hoki

12) Lapangan Rugby

13) Lapangan Atletik

14) Stadion Tenis Indoor

15) Lapangan Baseball

16) Lapangan Softball

17) Monumen Hijau

18) Taman Tropis

19) Taman Kridaloka

20) Bukit Persahabatan

21) Taman Anggrek

Gambar 1. Lokasi dan Orientasi Fasilitas Olahraga Kompleks Gelora Bung Karno (https://tataruang.jakarta.go.id, Hasil Observasi, 2018)

Berdasarkan Surat Keputusan Gubernur DKI Jakarta Nomor 475 Tahun 1993 tentang Penetapan Bangunan-Bangunan Bersejarah di Daerah Khusus Ibukota Jakarta Sebagai Benda Cagar Budaya, Kompleks GBK (saat itu bernama resmi Kompleks Gelora Senayan) ditetapkan sebagai benda cagar budaya yang dilindungi, tepatnya bagi keenam venue yang dibangun sejak awal, yaitu Istana Olahraga (Istora), Stadion Renang (Akuatik), Stadion Madya, Stadion Tenis (outdoor), Gedung Basket, dan Stadion Utama. Penetapan cagar budaya tersebut berimbas kepada perubahan-perubahan yang terjadi terhadap Kawasan GBK tidak boleh dilakukan sembarangan. Berbagai perbaikan dan perubahan yang selama ini terjadi tidak sampai mengubah fasad bangunan. Letak venue-venue cagar budaya yang terdapat di Kompleks GBK dapat dilihat dalam Gambar 2.

\subsection{Metode Penelitian}

Penelitian ini dilakukan dengan cara mengeksplorasi status sekelompok manusia, suatu objek, suatu set kondisi, suatu sistem pemikiran ataupun suatu peristiwa pada masa sekarang (Nazir, 2003). Penyajian data akan disampaikan secara deskriptif, yaitu menggambarkan kondisi atau data yang telah terkumpul sebagaimana adanya (Sugiyono, 2016). Jenis data yang digunakan adalah data primer dan data sekunder. Data primer merupakan data yang diperoleh secara langsung dari sumber data, artinya peneliti berusaha untuk memperoleh data secara langsung dari sumber data di lapangan. Pengumpulan data primer dalam penelitian ini dilakukan melalui: 


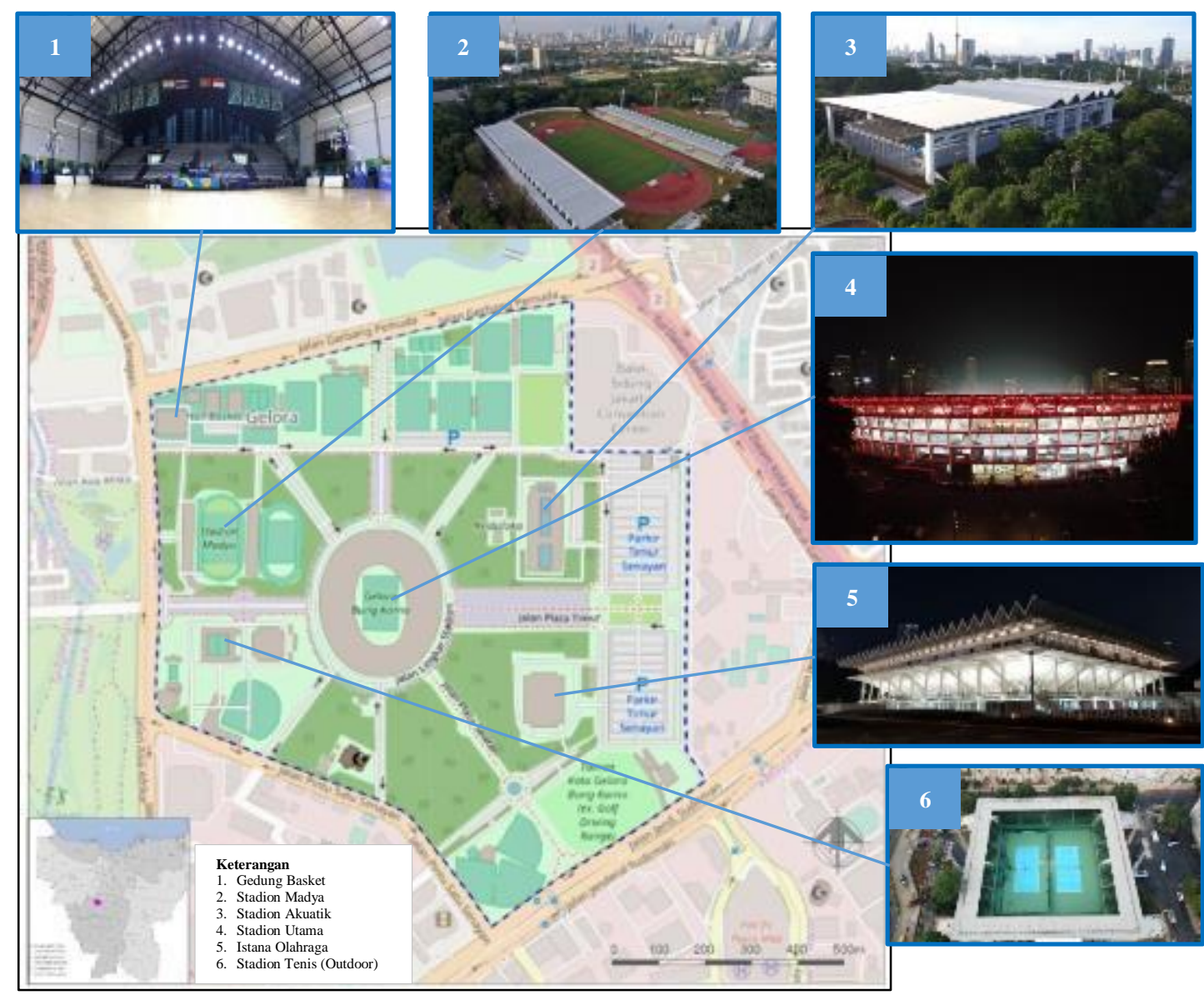

Gambar 2. Letak Venue Cagar Budaya di Kompleks Gelora Bung Karno (https://tataruang.jakarta.go.id, dokumentasi PUPR, 2018)

a. Kuesioner

Penyebaran kuesioner ditujukan kepada masyarakat DKI Jakarta yang sedang maupun pernah beraktifitas di Kompleks GBK dalam 5 tahun terakhir. Data yang dibutuhkan antara lain karakteristik pengunjung, aktivitas yang dilakukan, serta mengenai persepsi pengunjung terhadap makna dan fungsi kawasan sebagai urban heritage, menggunakan indikator tolok ukur konservasi.

b. Wawancara

Wawancara adalah proses memperoleh keterangan untuk tujuan penelitian dengan cara tanya jawab antara pewawancara dengan informan. Dalam penelitian ini, wawancara dilakukan kepada pihak pengelola guna mengetahui karakteristik kawasan yang lebih detail. Wawancara dilakukan dengan menggunakan pertanyaan-pertanyaan yang sifatnya fleksibel sesuai kondisi di lapangan agar bisa mendapatkan informasi yang objektif.

c. Observasi Lapangan

Observasi lapangan merupakan kegiatan pengamatan langsung oleh peneliti terhadap kondisi fisik dan aktivitas di Kawasan GBK. Teknik pengumpulan data melalui observasi lapangan dilakukan untuk mengetahui kondisi dan aktifitas yang terlihat secara nyata. Selain itu, dalam observasi lapangan juga perlu dilakukan pengambilan gambar/dokumentasi yang bertujuan untuk memperkuat fakta dari fenomena yang ada di lapangan. 
Selain data primer, penelitian ini juga menggunakan data sekunder, diperoleh peneliti tidak secara langsung, tapi melalui media perantara. Dalam penelitian ini, data sekunder diperoleh melalui kajian literatur, dengan mengumpulkan beberapa sumber referensi yang berkaitan dengan objek penelitian yaitu tentang pusaka perkotaan dan cagar budaya. Di samping itu, peneliti juga melakukan kajian normatif peraturan-peraturan yang terkait dengan objek dan sasaran penelitian.

Populasi dalam penelitian ini adalah masyarakat DKI Jakarta yang pernah berkunjung ke Kompleks Gelora Bung Karno (GBK) dalam 5 tahun terakhir. Teknik pengambilan sampel pada penelitian ini menggunakan non probability sampling, dimana yang menjadi responden hanya masyarakat umum DKI Jakarta yang pernah berkunjung ke Kompleks GBK dalam 5 tahun terakhir. Alasannya adalah agar memungkinkan diperoleh gambaran pemanfaatan kawasan yang optimal, dengan mempertimbangkan adanya area di dalam Kompleks GBK yang sempat ditutup ketika dilakukan renovasi pada tahun 2016 2018. Pengambilan sampel menggunakan teknik accidental sampling, yaitu teknik pengambilan sampel berdasarkan kebetulan, sehingga siapa saja yang bertemu dengan peneliti di wilayah penelitian dapat dijadikan sampel bila orang tersebut dipandang cocok sebagai sumber data (Sugiyono, 2016). Dengan menggunakan rumus perhitungan Slovin, diperoleh sampel yang akan digunakan sebagai responden adalah sebanyak 100 kuesioner yang dibagikan kepada 100 masyarakat DKI Jakarta yang pernah berkunjung ke Kompleks GBK dalam 5 tahun terakhir.

Dalam penelitian ini, metode analisis data yang dilakukan ada dua macam, yaitu:

a. Identifikasi karakteristik masyarakat DKI Jakarta yang mengunjungi Kompleks Gelora Bung Karno

Data diperoleh melalui kuesioner yang disampaikan kepada responden. Analisis dilakukan dengan metode distribusi frekuensi terhadap data-data nominal, yang bertujuan untuk menampilkan dan mendeskripsikan karakteristik sampel penelitian yang terdiri atas satu variabel saja. Frekuensi kemunculan terbanyak dianggap sebagai karakter dominan yang menggambarkan karakter populasi secara keseluruhan.

b. Analisis persepsi masyarakat DKI Jakarta terhadap makna dan fungsi Kompleks Gelora Bung Karno sebagai urban heritage

Data diperoleh melalui kuesioner yang disampaikan kepada responden. Data yang digunakan pada analisis-analisis ini adalah data ordinal yang menggunakan skala likert. Skala likert dipilih sebagai dasar analisis ini karena bertujuan untuk mengukur sikap, pendapat, dan persepsi orang terkait fenomena sosial yang selanjutnya disebut sebagai variabel penelitian (Sugiyono, 2016).

Untuk keperluan analisis, jawaban dengan skala likert diberikan skor, yaitu 5 untuk Sangat Setuju, 4 untuk Setuju, 3 untuk Biasa Saja, 2 untuk Tidak Setuju, dan 1 untuk Sangat Tidak Setuju. Dengan jumlah responden 100 orang, pengelompokan nilai persepsi adalah tergambar dalam Tabel 1.

Tabel 1. Pengelompokan Penilaian Persepsi (Hasil Analisis, 2018)

\begin{tabular}{cccc}
\hline Nilai & Skor & Dalam $\%$ & Persepsi \\
\hline $421-500$ & 5 & $84,20-100$ & Sangat baik \\
$341-420$ & 4 & $68,20-84,00$ & Baik \\
$261-340$ & 3 & $52,20-68,00$ & Cukup baik \\
$181-260$ & 2 & $36,20-52,00$ & Tidak baik \\
$100-180$ & 1 & $20,00-36,00$ & Sangat tidak baik \\
\hline
\end{tabular}

\section{HASIL DAN PEMBAHASAN}

3.1. Karakteristik Masyarakat DKI Jakarta yang Mengunjungi Kompleks Gelora Bung Karno

Identifikasi karakteristik masyarakat DKI Jakarta ini terdiri atas identifikasi karakteristik sosioekonomi dan karakteristik kunjungan. Karakteristik sosio-ekonomi meliputi jenis kelamin, usia, pekerjaan, penghasilan, pendidikan terakhir, dan status pernikahan (Ismayanti, 2010). Karakteristik kunjungan meliputi tempat tinggal pengunjung, frekuensi kunjungan, partner berkunjung, moda transportasi, serta 
tujuan berkunjung. Berikut ini hasil kuesioner terkait karakteristik pengunjung Kompleks GBK tergambar dalam Tabel 2.

Tabel 2. Karakteristik Masyarakat DKI Jakarta yang Mengunjungi Kompleks Gelora Bung Karno (Hasil Analisis, 2018)

\begin{tabular}{|c|c|c|c|}
\hline Karakteristik & Variabel & Indikator & Prosentase (\%) \\
\hline \multirow{22}{*}{$\begin{array}{l}\text { Karakteristik } \\
\text { Sosio- } \\
\text { Ekonomi }\end{array}$} & \multirow{2}{*}{ Jenis kelamin } & Laki-laki & 53 \\
\hline & & Perempuan & 47 \\
\hline & \multirow{4}{*}{ Usia } & di bawah 20 tahun & 11 \\
\hline & & $20-35$ tahun & 49 \\
\hline & & $35-50$ tahun & 37 \\
\hline & & $50-60$ tahun & 3 \\
\hline & \multirow[t]{5}{*}{ Pekerjaan } & Belum Bekerja & 32 \\
\hline & & Wiraswasta & 10 \\
\hline & & Karyawan Swasta & 37 \\
\hline & & Pegawai Negeri & 14 \\
\hline & & Ibu Rumah Tangga & 7 \\
\hline & \multirow[t]{5}{*}{ Penghasilan } & di bawah Rp 1.000.000,00 & 32 \\
\hline & & Rp $1.000 .000,00-R p 3.000 .000,00$ & 9 \\
\hline & & $\operatorname{Rp} 3.000 .000,00-\operatorname{Rp} 5.000 .000,00$ & 19 \\
\hline & & $\operatorname{Rp} 5.000 .000,00-\operatorname{Rp} 7.000 .000,00$ & 17 \\
\hline & & di atas $\mathrm{Rp} 7.000 .000,00$ & 23 \\
\hline & \multirow[t]{3}{*}{ Pendidikan terakhir } & Tamat SLTP & 6 \\
\hline & & Tamat SLTA & 37 \\
\hline & & Tamat Perguruan Tinggi & 57 \\
\hline & \multirow[t]{3}{*}{ Status pernikahan } & Belum Menikah & 39 \\
\hline & & Menikah & 59 \\
\hline & & Janda / Duda & 2 \\
\hline \multirow{24}{*}{$\begin{array}{l}\text { Karakteristik } \\
\text { Kunjungan }\end{array}$} & \multirow[t]{3}{*}{ Jarak tempat tinggal } & $0-5 \mathrm{~km}$ & 21 \\
\hline & & $5-10 \mathrm{~km}$ & 44 \\
\hline & & $>10 \mathrm{~km}$ & 35 \\
\hline & \multirow[t]{3}{*}{ Frekuensi kunjungan } & Tidak menentu (insidentil) & 69 \\
\hline & & Sebulan sekali & 15 \\
\hline & & Seminggu sekali & 16 \\
\hline & \multirow[t]{5}{*}{ Partner berkunjung } & Sendiri & 12 \\
\hline & & Pasangan & 9 \\
\hline & & Teman & 52 \\
\hline & & Keluarga & 16 \\
\hline & & Rombongan & 11 \\
\hline & \multirow[t]{7}{*}{ Moda transportasi } & Jalan kaki & 3 \\
\hline & & Sepeda & 10 \\
\hline & & Sepeda motor & 21 \\
\hline & & Mobil pribadi & 26 \\
\hline & & Bus & 19 \\
\hline & & Ojek online & 10 \\
\hline & & Taksi online & 11 \\
\hline & \multirow[t]{6}{*}{ Tujuan berkunjung } & Berolahraga & 29 \\
\hline & & Menonton pertandingan & 22 \\
\hline & & Bersenang-senang & 16 \\
\hline & & Kuliner & 4 \\
\hline & & Penelitian & 4 \\
\hline & & Seni dan Budaya & 6 \\
\hline
\end{tabular}


Setionurjaya, Tyas / Jurnal Pembangunan Wilayah dan Kota, Vol 14, No 2, 2018, 83 - 93

\begin{tabular}{|c|l|l|c|}
\hline Karakteristik & Variabel & \multicolumn{1}{|c|}{ Indikator } & Prosentase (\%) \\
& & Berkumpul dan bersosialisasi & 9 \\
\cline { 3 - 4 } & & Event tertentu & 10 \\
\hline
\end{tabular}

Dari tabel di atas, dapat diketahui bahwa dari 100 orang responden, mayoritas adalah laki-laki, usia remaja hingga dewasa, pekerjaan karyawan swasta, penghasilan di bawah Rp 1.000.000,00, tamatan Perguruan Tinggi, serta sudah menikah. Penghasilan di bawah Rp 1.000.000,00 tersebut berasal dari responden yang belum bekerja/pelajar/mahasiswa. Jadi penghasilan tersebut tidak mewakili penghasilan mayoritas dari karyawan swasta, karena jawaban responden karyawan swasta atas penghasilan mereka beragam, yang semuanya di atas Rp 1.000.000,00. Berdasarkan hal tersebut, terlihat bahwa sebagian besar responden adalah laki-laki berpendidikan tinggi, sudah menikah, bekerja sebagai karyawan swasta dengan penghasilan beragam.

Dari aspek karakteristik kunjungan, dapat diketahui bahwa mayoritas responden tinggal di jarak tidak terlalu jauh dari Kompleks GBK, dengan frekuensi kunjungan tidak menentu, naik mobil pribadi, bersama teman, dengan tujuan untuk berolahraga. Mengacu pada hasil dominan dari kedua karakteristik tersebut serta prosentasenya, terlihat bahwa rata-rata pengunjung Kompleks GBK adalah masyarakat DKI Jakarta yang berpendidikan, sudah menikah, dan bekerja, yang tidak secara rutin berkunjung, bersama dengan temannya, menggunakan kendaraan pribadi, dan dengan tujuan yang cukup beragam. Hasil ini cukup wajar, karena Kompleks Gelora Bung Karno merupakan ruang publik yang terletak di tengah kota yang mudah dicapai, dekat dengan area perkantoran dan bisnis, di mana karyawan bisa meluangkan waktu di sela-sela atau setelah bekerja untuk berolahraga atau berinteraksi di kawasan tersebut.

\subsection{Analisis Persepsi Masyarakat Terhadap Makna dan Fungsi Kompleks Gelora Bung Karno sebagai Urban Heritage}

Pemeliharaan venue dan fasilitas olahraga, apalagi yang telah berusia puluhan tahun, memang memerlukan penanganan yang tepat dan menyesuaikan dengan perkembangan zaman, di samping juga untuk mengatasi penurunan kualitas bangunan akibat waktu. Walaupun begitu, adaptasi bangunan terhadap perkembangan kebutuhan dan fasilitas modern yang mengesampingkan detail historis dan koneksi ke masa lalu akan mengecewakan masyarakat yang fasilitasnya seharusnya dapat diselamatkan, di sisi lain merupakan kewajiban moral bagi pengambil keputusan terkait untuk menjaga warisan masa lampau tersebut (Pfleegor, Seifried, \& Soebbing, 2013). Warisan tersebut penting untuk dijaga, karena terkait dengan identitas tempat itu sendiri. Ketika masyarakat berpindah tempat, eksistensi tempat yang ditinggalkan harus tetap ada, berakar pada dimensi lokalnya, agar maknanya senantiasa dibawa oleh masyarakat (Porta, 1999).

Dalam proses pembangunan dan pengembangan perkotaan, ikatan budaya terutama pada masyarakat dengan pengetahuan terbatas harus dipertimbangkan, termasuk membangun ikatan sosial dengan kawasan urban heritage, yang dapat meningkatkan kesadaran masyarakat lokal akan konservasi dan pembangunan ruang publik kota yang berkelanjutan (Cheung \& Hui, 2018). Di lingkup dimensi perkotaan, ruang publik penting bagi perkembangan dan keseimbangan kota, yang berfungsi sebagai zona penyangga dan area lobi dari pusat kota, serta signifikan untuk lingkungan kota yang sehat, sehingga akan memperindah lingkungan perkotaan dan membuat masyarakat nyaman untuk tinggal, bekerja, dan beristirahat (Ramlee, Omar, Yunus, \& Samadi, 2015). Penataan tempat terkait penyediaan ruang publik merupakan hal abstrak dan normatif, mengacu pada identitas, makna, dan perlekatan tempat tersebut, yang menghargai proses bottom-up pembentukannya, dan pada akhirnya dapat mendukung partisipasi masyarakat (Zamanifard, Alizadeh, \& Bosman, 2018).

Dalam mengidentifikasi persepsi masyarakat terhadap makna dan fungsi Kompleks GBK sebagai urban heritage, digunakan variabel tolok ukur konservasi yang meliputi tolok ukur bersifat fisik (kelangkaan, kesejarahan, estetika, superlativitas, kejamakan, kualitas pengaruh) dan non fisik (nilai sosial, nilai komersial, dan nilai ilmiah). Hasil identifikasi dapat dilihat pada Tabel 3. 
Berdasarkan tabel, dapat diketahui bahwa untuk kesembilan tolok ukur konservasi yang ditanyakan, secara personal, sebagian besar responden pada masing-masing indikator menjawab setuju. Artinya, banyak masyarakat, terutama yang berpendidikan dan sudah bekerja (sesuai karakteristik pengunjung dominan) sadar dan mengetahui bahwa Kompleks GBK memang layak sebagai urban heritage yang ditetapkan sebagai cagar budaya. Walaupun begitu, masih adanya responden yang menjawab tidak setuju dan sangat tidak setuju menunjukkan bahwa masih ada beberapa masyarakat yang menganggap bahwa Kompleks GBK bukan urban heritage, yang bisa saja disebabkan oleh kurangnya pemahaman mereka atas aspek heritage atau cagar budaya.

Di sisi lain, ketika dinilai secara rata-rata terhadap keseluruhan responden, rata-rata mempunyai persepsi baik pada seluruh tolok ukur, kecuali pada indikator kejamakan, di mana nilainya 328 dan persepsi rata-rata adalah cukup baik (mengacu ke Tabel 1). Persepsi menunjukkan bahwa masyarakat tidak terlalu memahami aspek kejamakan dari Kompleks GBK; menurut mereka tidak terlalu mewakili suatu jenis atau ragam. Hal ini dimungkinkan karena bentuk dan ukuran venue-venue olahraga di dalam kompleks harus mengikuti standar yang sudah ditentukan oleh induk olahraga masing-masing, sehingga dinilai para responden kurang bercirikan langgam Indonesia ataupun kolonial. Walaupun begitu, nilai total rata-rata adalah 391. Berdasarkan Tabel 1, nilai tersebut termasuk dalam kelompok persepsi baik. Berarti, dengan beragamnya karakteristik pengunjung, rata-rata para responden mempunyai persepsi bahwa Kompleks GBK memang mempunyai makna dan fungsi sebagai urban heritage.

Tabel 3. Tanggapan Responden terhadap Tolok Ukur Konservasi (Hasil Analisis, 2018)

\begin{tabular}{|c|c|c|c|c|c|c|c|c|c|c|c|c|c|c|c|c|c|c|}
\hline & 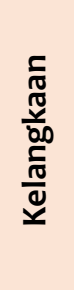 & $\frac{\bar{\pi}}{\bar{z}}$ & 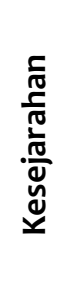 & $\frac{\bar{\pi}}{\bar{z}}$ & 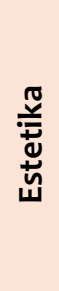 & $\frac{\bar{\pi}}{\bar{z}}$ & 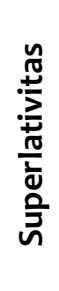 & $\frac{\bar{\pi}}{\bar{z}}$ & 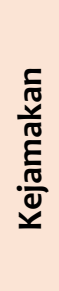 & $\frac{\bar{\pi}}{\bar{z}}$ & 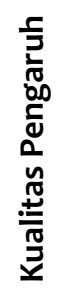 & $\frac{\bar{\pi}}{\bar{z}}$ & 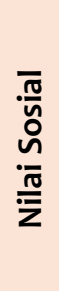 & $\frac{\bar{\pi}}{\bar{z}}$ & 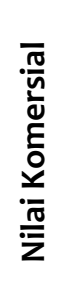 & $\frac{\bar{\pi}}{\bar{z}}$ & 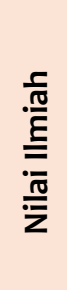 & $\frac{\bar{\pi}}{\bar{z}}$ \\
\hline $\begin{array}{l}\text { Sangat } \\
\text { Setuju }\end{array}$ & 15 & 75 & 18 & 90 & 16 & 80 & 28 & 140 & 6 & 30 & 23 & 115 & 22 & 110 & 24 & 120 & 31 & 155 \\
\hline Setuju & 44 & 176 & 67 & 268 & 46 & 184 & 58 & 232 & 43 & 172 & 68 & 272 & 66 & 264 & 57 & 228 & 61 & 244 \\
\hline $\begin{array}{c}\text { Biasa } \\
\text { Saja }\end{array}$ & 31 & 93 & 11 & 33 & 35 & 105 & 14 & 42 & 27 & 81 & 7 & 21 & 12 & 36 & 13 & 39 & 6 & 18 \\
\hline $\begin{array}{l}\text { Tidak } \\
\text { Setuju }\end{array}$ & 8 & 16 & 4 & 8 & 3 & 6 & 0 & 0 & 21 & 42 & 2 & 4 & 0 & 0 & 5 & 10 & 1 & 2 \\
\hline $\begin{array}{l}\text { Sangat } \\
\text { Tidak } \\
\text { Setuju }\end{array}$ & 2 & 2 & 0 & 0 & 0 & 0 & 0 & 0 & 3 & 3 & 0 & 0 & 0 & 0 & 1 & 1 & 1 & 1 \\
\hline Total & 100 & 362 & 100 & 399 & 100 & 375 & 100 & 414 & 100 & 328 & 100 & 412 & 100 & 410 & 100 & 398 & 100 & 420 \\
\hline $\begin{array}{l}\text { Total } \\
\text { Nilai }\end{array}$ & \multicolumn{18}{|c|}{3518} \\
\hline $\begin{array}{l}\text { Rata- } \\
\text { rata }\end{array}$ & \multicolumn{18}{|c|}{391} \\
\hline
\end{tabular}

Keterangan: Nilai = Skor $\mathrm{x}$ Jumlah tanggapan responden, mengacu ke Tabel 1

\section{KESIMPULAN}

Secara rata-rata, masyarakat DKI Jakarta yang datang ke Kompleks GBK merupakan masyarakat yang berpendidikan, sudah menikah, sudah bekerja, yang berkunjung secara insidentil, bersama dengan 
temannya, menggunakan kendaraan pribadi, dan dengan tujuan yang cukup beragam. Hal ini disebabkan karena Kompleks Gelora Bung Karno merupakan ruang publik yang terletak di tengah kota Jakarta yang mudah dicapai, dekat dengan area perkantoran dan bisnis, dengan karyawan bisa meluangkan waktu di sela-sela atau setelah bekerja untuk berolahraga atau berinteraksi di kawasan tersebut.

Berdasarkan kuesioner dengan indikator tolok ukur konservasi yang terdiri dari kelangkaan, kesejarahan, estetika, superlativitas, kejamakan, kualitas pengaruh, nilai sosial, nilai komersial, dan nilai ilmiah, banyak masyarakat sadar dan mengetahui bahwa Kompleks GBK layak sebagai urban heritage yang ditetapkan sebagai cagar budaya. Begitu juga ketika dirata-rata, dengan nilai 391, para responden mempunyai persepsi baik bahwa Kompleks GBK memang layak sebagai urban heritage yang ditetapkan sebagai cagar budaya. Walaupun begitu, masih ada masyarakat yang menjawab tidak setuju dan sangat tidak setuju terhadap tolok ukur konservasi tersebut. Hal ini menunjukkan kurangnya pemahaman mereka atas aspek heritage atau cagar budaya, yang jika dibiarkan dapat menyebar dan mengaburkan identitas kawasan sebagai urban heritage.

Dengan demikian, rekomendasi yang dapat dilakukan oleh pengelola (PPKGBK) terhadap masyarakat adalah memberikan informasi dan pemahaman tentang pentingnya cagar budaya, terutama yang terkait dengan Kompleks GBK, dengan cara meningkatkan promosi atau iklan layanan masyarakat yang menonjolkan unsur cagar budayanya. Dalam rangka promosi tersebut, pengelola juga dapat bekerjasama dengan pihak-pihak lain seperti mengikutsertakan Kompleks GBK ke dalam destinasi bus wisata keliling kota yang dimiliki Pemerintah Provinsi DKI Jakarta serta pengelolaan museum sejarah olahraga bersama Kementerian Pemuda dan Olahraga.

\section{PERNYATAAN RESMI}

Terima kasih kepada seluruh pihak, khususnya Kementerian Pekerjaan Umum dan Perumahan Rakyat Republik Indonesia yang telah memberi kesempatan dan dukungan pembiayaan selama peneliti melakukan penelitian tentang topik ini.

\section{REFERENSI}

Azizi, N. Z. M., Razak, A. A., Din, M. A. M., \& Nasir, N. M. (2016). Recurring Issues in Historic Building Conservation. Procedia - Social and Behavioral Sciences, 222, 587-595. https://doi.org/10.1016/j.sbspro.2016.05.217

Budihardjo, E. (2011). Penataan Ruang \& Pembangunan Perkotaan (Edisi Pert). Bandung: Alumni. Carmona, M., Heath, T., Oc, T., \& Tiesdell, S. (2003). Public Places - Urban Spaces: The Dimensions of Urban Design. Oxford: Architectural Press. https://doi.org/10.1111/febs.12167

Carr, S., Francis, M., Rivlin, L., \& Stome, A. (1992). Public Space. New York: Van Nostrand Reinhold.

Cheung, L. T. O., \& Hui, D. L. H. (2018). Influence of residents' place attachment on heritage forest conservation awareness in a peri-urban area of Guangzhou, China. Urban Forestry and Urban Greening, 33(June), 37-45. https://doi.org/10.1016/j.ufug.2018.05.004

Claudia, T., \& Luigi, P. (2016). A Novel Paradigm to Achieve Sustainable Regeneration in Historical Centres with Cultural Heritage. Procedia - Social and Behavioral Sciences, 223, 693-697.

https://doi.org/10.1016/j.sbspro.2016.05.243

Darmawan, E. (2003). Teori dan Kajian Ruang Publik Kota. Semarang: Universitas Diponegoro.

Darmawan, E. (2009). Ruang Publik dalam Arsitektur Kota. Semarang: Badan Penerbit Universitas Diponegoro.

Ismail, W. H. W., \& Nadarajah, J. R. s/o. (2016). Young Visitors in the City: Their Perceptions of Heritage Buildings. Procedia - Social and Behavioral Sciences, 234, 470-477.

https://doi.org/10.1016/j.sbspro.2016.10.265

Ismayanti. (2010). Pengantar Pariwisata. Jakarta: Grasindo.

Keputusan Gubernur Daerah Khusus Ibukota Jakarta Nomor 475 Tahun 1993 tentang Penetapan 
Bangunan-Bangunan Bersejarah di Daerah Khusus Ibukota Jakarta Sebagai Benda Cagar Budaya (1993).

Nazir, M. (2003). Metode Penelitian. Jakarta: Ghalia Indonesia.

Nour, H. (2012). Awqaf and Heritage Urban Conservation in Historic Muslim Cities. Thesis, Department of Architecture and Planning, Politecnico di Milano.

Petronela, T. (2016). The Importance of the Intangible Cultural Heritage in the Economy. Procedia Economics and Finance, 39(November 2015), 731-736. https://doi.org/10.1016/S2212-5671(16)30271-4

Pfleegor, A. G., Seifried, C. S., \& Soebbing, B. P. (2013). The moral obligation to preserve heritage through sport and recreation facilities. Sport Management Review, 16(3), 378-387. https://doi.org/10.1016/j.smr.2012.10.002

Porta, S. (1999). The community and public spaces: Ecological thinking, mobility and social life in the open spaces of the city of the future. Futures, 31(5), 437-456. https://doi.org/10.1016/S0016-3287(99)00004$X$

Ramlee, M., Omar, D., Yunus, R. M., \& Samadi, Z. (2015). Revitalization of Urban Public Spaces: An Overview. Procedia - Social and Behavioral Sciences, 201, 360-367. https://doi.org/10.1016/j.sbspro.2015.08.187

Sugiyono. (2016). Metode Penelitian Kuantitatif, Kualitatif dan R \& D. Bandung: Alfabeta.

Undang-Undang Nomor 11 tahun 2010 Tentang Cagar Budaya (2010). Indonesia.

Undang-Undang Republik Indonesia Nomor 3 Tahun 2005 Tentang Sistem Keolahragaan Nasional (2005).

Versaci, A. (2016). The Evolution of Urban Heritage Concept in France, Between Conservation and Rehabilitation Programs. Procedia -Social and Behavioral Sciences, 225(November 2015), 3-14. https://doi.org/10.1016/j.sbspro.2016.06.003

Zamanifard, H., Alizadeh, T., \& Bosman, C. (2018). Towards a framework of public space governance. Cities, (March 2017), 1-11. https://doi.org/10.1016/j.cities.2018.02.010 